\title{
Renin-angiotensin system regulates neurodegeneration in a mouse model of normal tension glaucoma
}

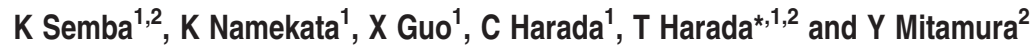

Glaucoma, one of the leading causes of irreversible blindness, is characterized by progressive degeneration of optic nerves and retinal ganglion cells (RGCs). In the mammalian retina, excitatory amino acid carrier 1 (EAAC1) is expressed in neural cells, including RGCs, and the loss of EAAC1 leads to RGC degeneration without elevated intraocular pressure (IOP). In the present study, we found that expressions of angiotensin II type 1 receptor (AT1-R) and Toll-like receptor 4 (TLR4) are increased in RGCs and retinal Müller glia in EAAC1-deficient (KO) mice. The orally active AT1-R antagonist candesartan suppressed TLR4 and lipopolysaccharide (LPS)-induced inducible nitric oxide synthase (iNOS) expressions in the EAAC1 KO mouse retina. Sequential in vivo retinal imaging and electrophysiological analysis revealed that treatment with candesartan was effective for RGC protection in EAAC1 KO mice without affecting IOP. In cultured Müller glia, candesartan suppressed LPS-induced iNOS production by inhibiting the TLR4-apoptosis signal-regulating kinase 1 pathway. These results suggest that the reninangiotensin system is involved in the innate immune responses in both neural and glial cells, which accelerate neural cell death. Our findings raise intriguing possibilities for the management of glaucoma by utilizing widely prescribed drugs for the treatment of high blood pressure, in combination with conventional treatments to lower IOP.

Cell Death and Disease (2014) 5, e1333; doi:10.1038/cddis.2014.296; published online 17 July 2014

Glaucoma is one of the leading causes of vision loss in the world. It is estimated that glaucoma affects nearly 70 million individuals worldwide, including at least 6.8 million who are bilaterally blind. ${ }^{1,2}$ The disease is characterized by the progressive degeneration of retinal ganglion cells (RGCs) and their axons, together with visual field loss, which are usually associated with elevated intraocular pressure (IOP). Glaucoma is affected by multiple genes and environmental factors, and there are several inherited and experimentally induced animal models of high IOP glaucoma. ${ }^{3}$ On the other hand, normal tension glaucoma (NTG) is a subtype of glaucoma that presents with statistically normal IOP. The prevalence of NTG is reported to be higher among the Japanese than among Caucasians. ${ }^{4,5}$ This raises a major problem that is faced by medical and public health sectors in Japan because simple screening programs based on detection of elevated IOP are not effective in a population where NTG is highly prevalent. In addition, these findings suggest a possibility that non-IOP-dependent factors may contribute to disease progression and that elucidating such factors is necessary to better understand the pathogenesis of glaucoma, especially in the context of NTG. ${ }^{5,6}$

It is well known that an immoderate release of excitatory amino acids, such as glutamate, can cause neuronal cell death. An excessively high extracellular concentration of glutamate chronically activates glutamate receptors and allows calcium entry into the cell causing an uncontrolled elevation of intracellular calcium levels., ${ }^{7,8}$ The glutamate transporter is the only mechanism for removal of glutamate from the extracellular fluid in the retina. ${ }^{9}$ In the inner plexiform layer where synapses exist across RGCs, at least three transporters are involved in this task: glutamate transporter 1 (GLT-1) located in the bipolar cell terminals; excitatory amino acid carrier 1 (EAAC1) in RGCs; and glutamate/aspartate transporter (GLAST) in Müller glial cells. ${ }^{10,11}$ We previously reported that GLAST and EAAC1 knockout (KO) mice show progressive RGC loss and optic nerve degeneration without elevated IOP, and not only glutamate neurotoxicity but also oxidative stress is involved in its mechanism. ${ }^{6}$ Glutamate neurotoxicity and oxidative stress have been proposed to contribute to retinal damage in various eye diseases including glaucoma. ${ }^{12}$ Together with the downregulation of glutamate transporters and glutathione levels observed in glaucoma patients, ${ }^{13}$ these mice seem to be useful as the animal models of NTG. $6,7,11,14$

Apoptosis signal-regulating kinase 1 (ASK1) has key roles in human diseases closely related to the dysfunction of cellular responses to oxidative stress and endoplasmic

\footnotetext{
${ }^{1}$ Visual Research Project, Tokyo Metropolitan Institute of Medical Science, Tokyo, Japan and ${ }^{2}$ Department of Ophthalmology, Institute of Health Biosciences, The University of Tokushima Graduate School, Tokushima, Japan

*Corresponding author: T Harada, Visual Research Project, Tokyo Metropolitan Institute of Medical Science, 2-1-6 Kamikitazawa, Setagaya-ku, Tokyo 156-8506, Japan. Tel: + 8136834 2338; Fax: + 8136834 2339; E-mail: harada-tk@igakuken.or.jp

Abbreviations: ASK1, apoptosis signal-regulating kinase 1; AT1-R, Angiotensin II type 1 receptor; EAAC1, excitatory amino acid carrier 1; GCL, ganglion cell layer; GLAST, glutamate/aspartate transporter; iNOS, inducible nitric oxide synthase; IOP, intraocular pressure; LPS, lipopolysaccharide; mfERG, multifocal electroretinogram; NO, nitric oxide; NTG, normal tension glaucoma; OCT, optical coherence tomography; RAS, renin-angiotensin system; RGC, retinal ganglion cell; TLR4, Toll-like receptor 4

Received 11.11.13; revised 13.4.14; accepted 05.5.14; Edited by A Verkhratsky
} 
reticulum stressors, including neurodegenerative diseases. ${ }^{15}$ We previously reported that ASK1 KO mice are less susceptible to ischemic injury and optic nerve injury. ${ }^{16,17}$ In addition, RGC degeneration was partly suppressed in GLAST/ASK1 double KO mice. ${ }^{14}$ Thus, interruption of ASK1 pathways could be beneficial for RGC protection during retinal degeneration including glaucoma. Furthermore, ASK1 directly binds to Toll-like receptor 4 (TLR4) and regulates the innate immune responses during neuroinflammation. ${ }^{18}$

The renin-angiotensin system (RAS) has a major role in the cardiovascular system. ${ }^{19}$ Renin, a proteolytic enzyme primarily released by the kidneys, cleaves angiotensinogen to angiotensin I (Angl). Angl is further processed by angiotensin-converting enzyme and angiotensin-converting enzyme 2 (ACE/ACE2) to different angiotensin cleavage products. Among them, angiotensin II (Angll) is the principal effector molecule of the RAS, acting on its target cells mainly via Angll type 1 receptor $(A T 1-R) .{ }^{20}$ In addition, Angll induces TLR4 expression in various cell types. ${ }^{21,22}$ Modulators of the RAS, such as ACE inhibitors or AT1-R antagonists, are utilized as prescribed drugs to treat high blood pressure. ${ }^{23} \mathrm{~A}$ recent study showed that candesartan, an AT1-R antagonist, protected rat retinal neurons from ischemia-reperfusion injury, ${ }^{24}$ but the detailed mechanisms are still unknown. Interestingly, polymorphisms in Angll receptors are reported in glaucoma patients, ${ }^{25}$ and ACE inhibitors may suppress the progression of visual field defects in NTG patients. ${ }^{26}$ These results suggest a possibility that the RAS is implicated in RGC death by an IOP-independent mechanism. In the present study, we show neuroprotective effects of candesartan in EAAC1 KO mice, an animal model of NTG, and we report a novel pathway for neuroprotection that involves innate immune responses in retinal glial cells.

\section{Results}

Retinal degeneration in EAAC1 KO mice. The retinas of EAAC1 KO mice show normal organization at 5 weeks of age $(5 \mathrm{~W})$ and retinal degeneration starts thereafter, as we previously reported. ${ }^{6,11}$ We first examined the cell number in the ganglion cell layer (GCL) and the thickness of the inner retinal layer (IRL) from 3 to $12 \mathrm{~W}$ (Figure 1a). The cell number in the GCL was significantly decreased in EAAC1 KO mice compared with WT mice after $8 \mathrm{~W}$ (Figure 1b). In addition, the thickness of the IRL was also significantly decreased after $8 \mathrm{~W}$ in EAAC1 $\mathrm{KO}$ mice (Figure 1c). We next examined the visual function of these mice at 8 and $12 \mathrm{~W}$ using the established noninvasive method multifocal electroretinograms (mfERGs). ${ }^{6,14,18}$ The visual function of EAAC1 $\mathrm{KO}$ mice was impaired in all visual fields compared with WT mice at 8 and $12 \mathrm{~W}$ (Figures 1d and e).

\footnotetext{
Neuroprotective effects of candesartan in EAAC1 KO mice. To investigate whether candesartan is capable of preventing the NTG-like phenotypes in EAAC1 KO mice, we administered candesartan or PBS (control) orally every day to EAAC1 KO mice from 5 to 8 or $12 \mathrm{~W}$ (Figure 2a). Histopathological analysis revealed that a small degree of RGC loss was observed in candesartan-treated mice, but the
}

number of surviving neurons in these mice was significantly higher than that in untreated (control) mice (Figures $2 \mathrm{~b}$ and $\mathrm{c}$ ). In addition, candesartan treatment prevented the thinning of the IRL (Figure 2d). We also visualized retinal layers using optical coherence tomography (OCT), a noninvasive imaging technique that can be used to acquire cross-sectional tomographic images of the retina in vivo. ${ }^{17}$ The average thickness of the ganglion cell complex (GCC), which includes the nerve fiber layer, GCL, and inner plexiform layer, was decreased in control eyes, but it was unchanged in candesartan-treated eyes, indicating that candesartan suppresses the retinal degeneration in EAAC1 KO mice (Figure 3a). For quantitative analysis, GCC was measured by scanning the retina in a circle centering around the optic nerve disk (Figure 3b), and the average GCC thickness was determined from acquired images (Figure 3c). GCC thickness at 8 and $12 \mathrm{~W}$ was significantly reduced in control mice, but it was unchanged in candesartan-treated mice (Figure 3d). We also analyzed the visual function of these mice at 8 and $12 \mathrm{~W}$. The visual function of candesartantreated mice was better than that of control mice in all visual fields (Figures $4 a$ and $b$ ). We next examined the effects of candesartan on IOP. The IOP values of candesartan-treated mice were not significantly altered compared with those of control mice (Figure 4c). These results suggest that candesartan prevents NTG-like pathology in EAAC1 KO mice and this neuroprotective effect is IOP-independent.

AT1-R and TLR4 expression in the retina of EAAC1 KO mice. To examine the mechanism of neuroprotective effects of candesartan, we first analyzed the mRNA expression of AT1-R in the retina of WT and EAAC1 KO mice at $5 \mathrm{~W}$. Compared with WT mice, AT1-R expression was significantly increased in EAAC1 $\mathrm{KO}$ mice (Figure 5a). As RGC degeneration in EAAC1 $\mathrm{KO}$ mice is known to associate with oxidative stress, we next examined the effects of oxidative stress on AT1-R expression. Intraocular injection of a nitric oxide (NO) donor, NOR4, to WT mice significantly upregulated AT1-R expression (Figure $5 \mathrm{~b}$ ). These results indicate that oxidative stress in EAAC1 KO mice causes the elevation of AT1-R.

Previous studies have shown that Angll upregulates TLR4 expression, and gene polymorphisms in TLR4 are associated with the risk of glaucoma. ${ }^{21,22,27,28}$ So we examined the protein expression of TLR4 in the retina of WT, EAAC1 KO mice and candesartan-treated (1 week from $5 \mathrm{~W}$ ) EAAC1 KO mice. A significant increase of TLR4 expression was observed in untreated EAAC1 KO mice, but candesartan treatment suppressed this increase (Figure $5 \mathrm{c}$ ). To examine the effects of TLR4 signaling on the expression of cytotoxic factors, we next measured iNOS mRNA expression in the retina after intraocular injection of LPS (a ligand for TLR4). The mRNA expression of iNOS was increased by LPS in a dosedependent manner in both WT and EAAC1 KO mice. However, a significant increase was observed with a low dose of LPS (1 ng) in EAAC1 KO mice whereas no increase was observed in WT mice (Figure $5 \mathrm{~d}$ ). In addition, such an upregulation was inhibited by candesartan treatment (Figure 5e). Taken together, these results suggest that expression of AT1-R, TLR4 and iNOS are all upregulated in 
a
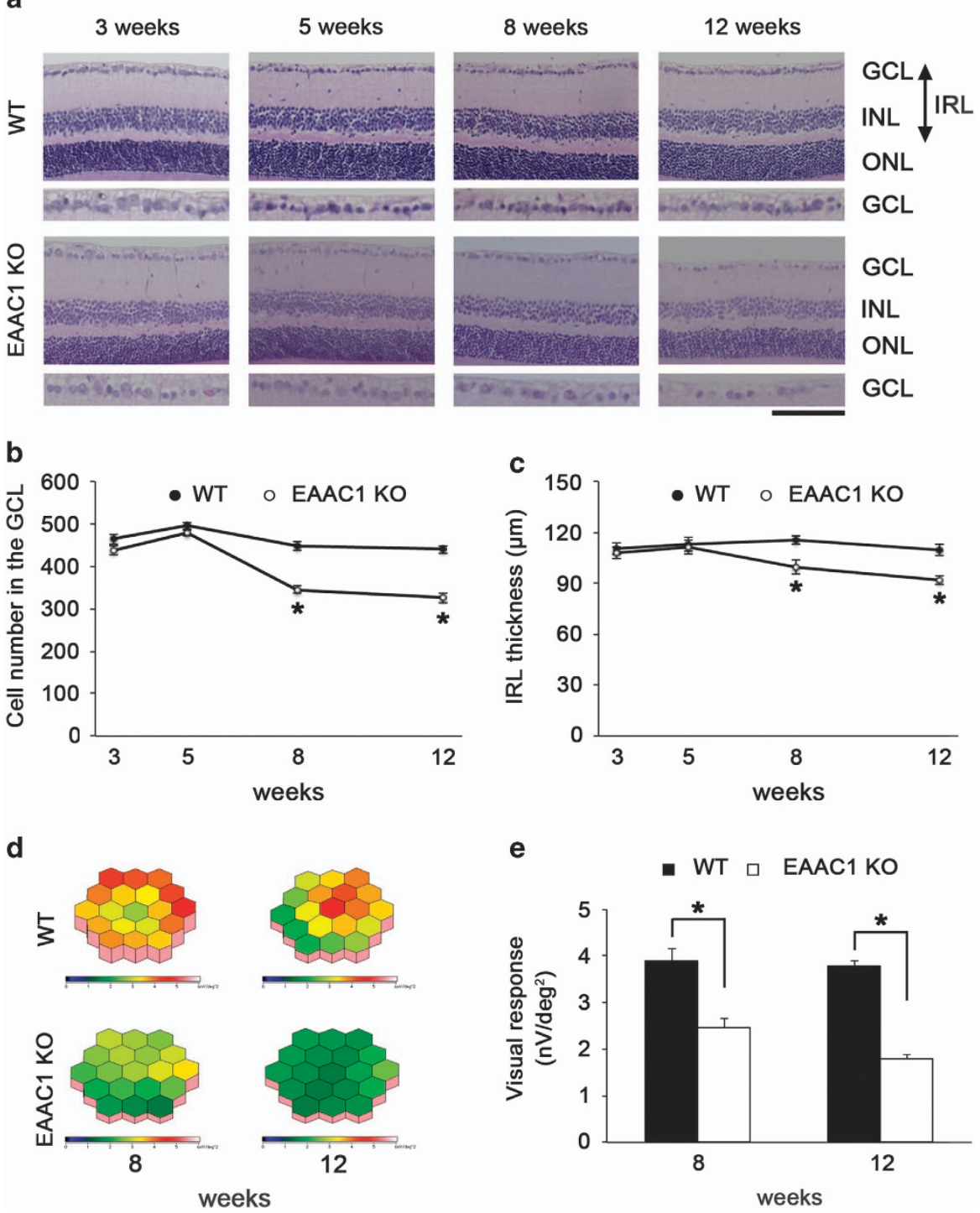

Figure 1 Glaucomatous retinal degeneration in EAAC1 KO mice. (a) H\&E staining of retinal sections from WT and EAAC1 KO mice at 3, 5, 8 and 12 W. Scale bar, 100 and $50 \mu \mathrm{m}$ in the upper and immediately lower panels, respectively. GCL, ganglion cell layer; INL, inner nuclear layer; ONL, outer nuclear layer; IRL, inner retinal layer. (b) Quantification of the RGC number in WT and EAAC1 KO mice. The number of neurons in the GCL was counted in retinal sections from one ora serrata through the optic nerve to the other ora serrata. (c) Quantification of the IRL thickness. (d) Averaged visual responses of the second-order kernel examined by multifocal electroretinogram are demonstrated using three-dimensional plots. The degree of retinal function is presented in the color bar. A higher score (red) indicates highly sensitive visual function, and a lower score (green) indicates retinal dysfunction. (e) Quantitative analysis of the visual response amplitude. Values are given in $\mathrm{nV}$ per square degree $\left(\mathrm{nV} / \mathrm{deg}^{2}\right)$. The data are presented as means \pm S.E.M. of $6-12$ samples for each experiment. ${ }^{*} P<0.05$

EAAC1 KO mice, and candesartan suppresses TLR4 and iNOS expressions by inhibiting AT1-R-mediated responses.

Expression of AT1-R, TLR4 and iNOS in the retina. To identify the cell type distribution of AT1-R and TLR4 in the retina of WT and EAAC1 KO mice, we performed immunohistochemistry with antibodies against AT1-R, TLR4 and retinal cell markers. AT1-R and TLR4 immunopositive (IP) cells were double-labeled with GS or GLAST (markers for Müller cells) and $\beta$ III tubulin (a marker for RGCs; Figure 6a). Compared with WT mice, AT1-R and TLR4 expressions in EAAC1 KO mice seemed to be increased in both Müller cells and RGCs. We next examined the distribution of iNOS after intraocular injection of LPS (1 ng). Compared with WT mice,
iNOS expression was clearly increased in the inner retina of EAAC1 KO mice (Figure 6b). In addition, iNOS IP cells were strongly double-labeled with GLAST (Figure 6c), indicating that iNOS expression was mainly induced in Müller cells.

We next prepared cultured Müller cells and RGCs, and further confirmed the specificity of cell type-specific markers used and the purity of our cultured cells (Figures $6 d$ and e). mRNA expression of $\beta$ III tubulin (RGC marker) was hardly detected in cultured Müller cells (Figure 6e). RT-PCR analysis of AT1-R and TLR4 in cultured Müller cells, cultured RGCs and whole retinas revealed that AT1-R was strongly expressed in both cultured Müller cells and RGCs, whereas TLR4 was mainly detected in cultured Müller cells (Figure 6e). 
a

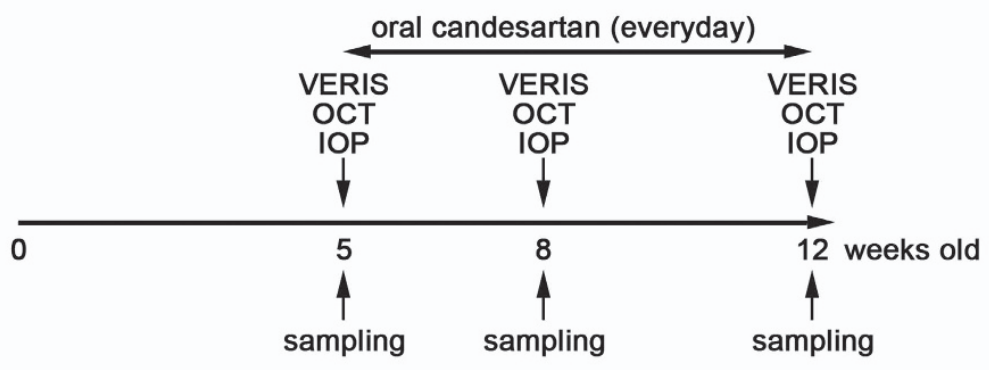

b

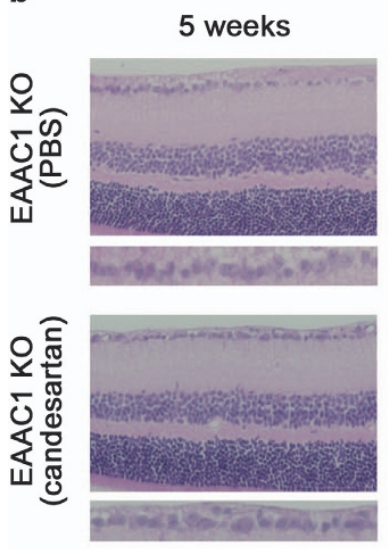

8 weeks
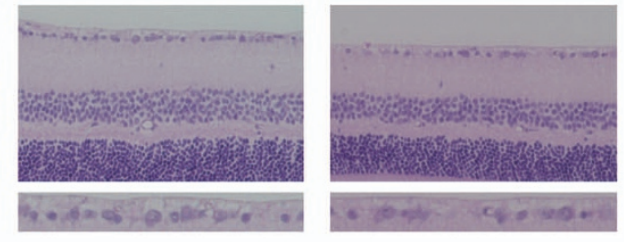

GCLA

INL IRL

ONL

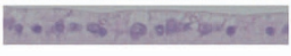

GCL
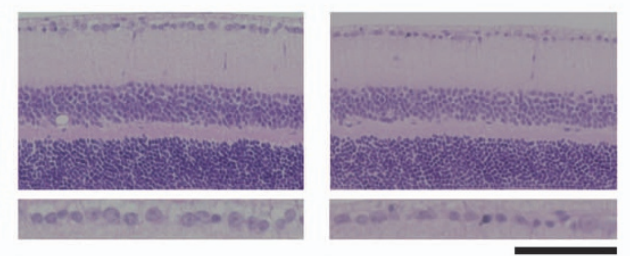

GCL

c

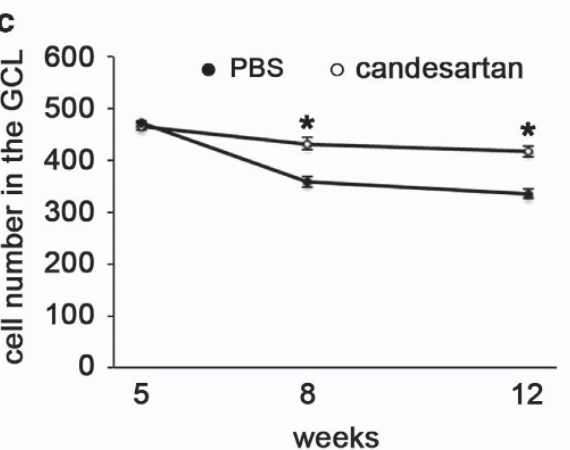

d

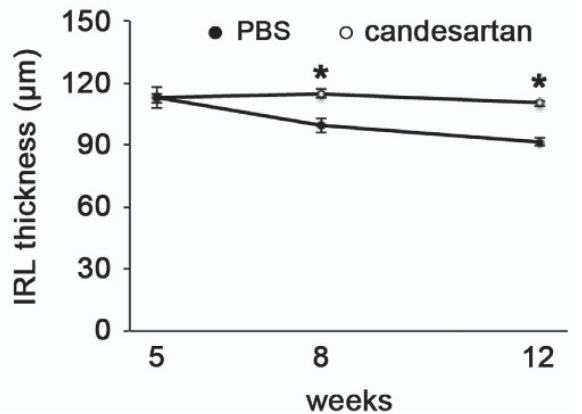

Figure 2 Effects of candesartan on RGC degeneration in EAAC1 KO mice. (a) Animal protocols. PBS or candesartan was administered orally every day from 5 W. The mice were euthanized at 5, 8 and 12 W. (b) H\&E staining of retinal sections. Administration of candesartan prevented RGC loss in EAAC1 KO mice. Scale bar, 100 and $50 \mu \mathrm{m}$ in the upper and immediately lower panels, respectively. (c, d) Quantification of the RGC number (c) and IRL thickness (d). The data are presented as means \pm S.E.M. of six samples for each experiment. ${ }^{*} P<0.05$

Effects of TLR4-ASK1 signaling in Müller cells. The RAS is involved in oxidative stress-induced cell death in cultured RGCs. ${ }^{29}$ However, our present findings suggest that candesartan may be effective also in Müller cells. To determine this possibility, we first examined the effects of Angll on TLR4 protein expression in cultured Müller cells, and found a dose-dependent increase of TLR4 (Figures 7a and $b$ ). We next measured the expression of TLR4 after pretreatment with candesartan $(10 \mu \mathrm{M})$ for $1 \mathrm{~h}$ before the stimulation with Angll (1000 nM). Candesartan inhibited Angll-induced upregulation of TLR4 expression (Figures 7c and d). We previously reported that the TLR4-ASK1 pathway is involved in the LPS-induced iNOS production in the retina. ${ }^{17,18}$ To determine whether the same pathway exists in Müller cells, we examined LPS-induced iNOS expression in cultured Müller cells. LPS-induced iNOS mRNA expression was increased in a dose-dependent manner, and a significant increase was detected when co-stimulated with Angll $(1000 \mathrm{nM}$; Figure $7 \mathrm{e})$. We also measured LPS $(1000 \mathrm{ng} / \mathrm{ml}$ for $6 \mathrm{~h})$-induced iNOS expression after pretreatment with candesartan for $1 \mathrm{~h}$ before stimulating with Angll $(1000 \mathrm{nM})$. Candesartan inhibited the additional upregulation of LPS-induced iNOS expression by Angll (Figure 7f). We performed similar experiments using cultured Müller cells prepared from ASK1 KO mice, but LPS-induced iNOS expression was hardly detectable. These results suggest that TLR4-ASK1 signaling is involved in the iNOS production in Müller cells, and that candesartan may protect RGCs by inhibiting Angll-induced TLR4 upregulation and iNOS production in Müller cells in EAAC1 KO mice. 


\section{a}

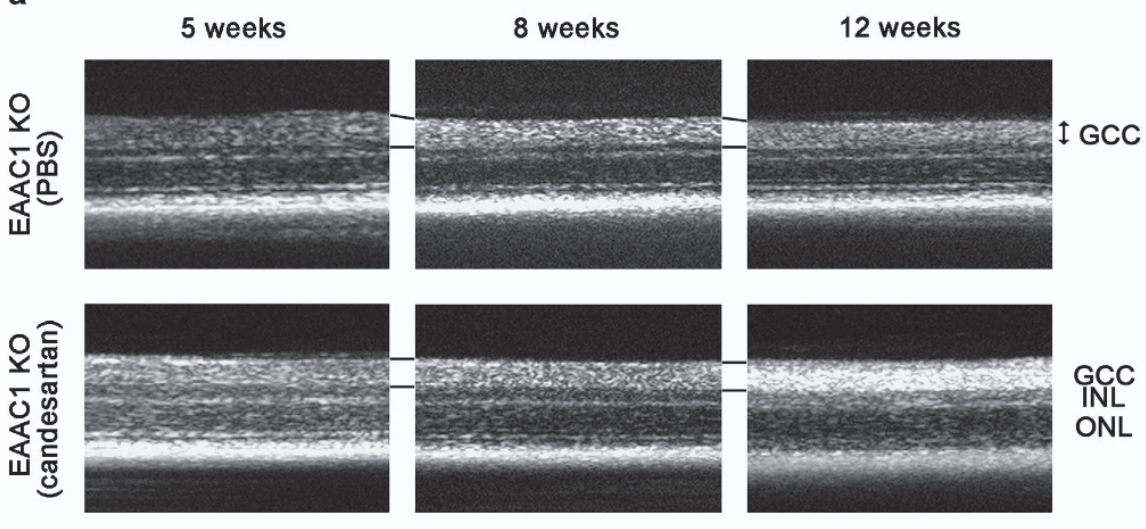

b

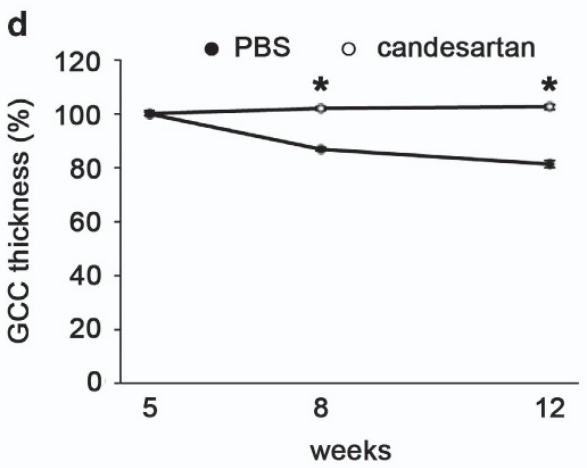

C

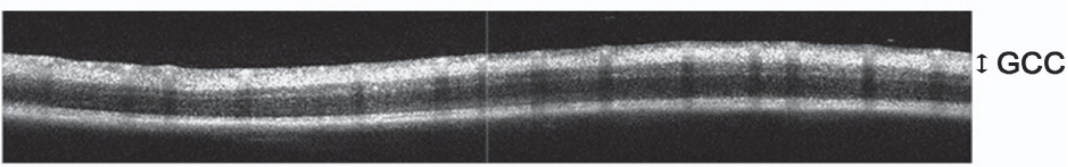

Figure 3 In vivo imaging of the retina in EAAC1 KO mice treated with candesartan. (a) OCT cross-sectional images of retinas at 5, 8 and 12 W. (b) An image of a circle centering around the optic nerve disk. (c) An OCT circular scan image captured from b. (d) Longitudinal evaluation of the GCC thickness by a circular scan. The data are presented as means \pm S.E.M. of six samples for each experiment. ${ }^{*} P<0.05$

\section{Discussion}

In this study, we showed that candesartan prevents progressive $R G C$ loss, thinning of the IRL and visual disturbances in EAAC1 KO mice without affecting IOP. To demonstrate these findings in the same animal, we utilized OCT and mfERG that permit in vivo, noninvasive, longitudinal and quantitative assessment of the changes in retinal morphology and function in EAAC1 $\mathrm{KO}$ mice. These techniques clearly visualized the effects of candesartan in the present study and they provide useful information in experimental animals as well as in clinical trials and management. ${ }^{30-32}$ In the EAAC1 KO mouse retina, AT1-R, TLR4 and LPS-induced iNOS expression levels were upregulated, and candesartan significantly suppressed the upregulation of TLR4 and iNOS expressions in these mice. We found that AT1-R and TLR4 were expressed in Müller glial cells as well as in RGCs, and LPS-induced iNOS was mainly expressed in Müller cells. In cultured Müller cells, Angll stimulated TLR4 and LPS-induced iNOS upregulation, which are suppressed by candesartan or ASK1 deficiency.

We previously reported that GLAST and EAAC1 have differential roles in preventing RGC degeneration. ${ }^{6,11}$ GLAST is essential not only to keep the extracellular glutamate concentration below the neurotoxic level, but also to maintain the glutathione levels in Müller cells by transporting glutamate, the substrate for glutathione synthesis, into the cells. In contrast, the main role of EAAC1 is to transport cysteine into RGCs as a precursor for neuronal glutathione synthesis. Thus, GLAST deficiency leads to RGC degeneration caused by both neurotoxicity and oxidative stress whereas EAAC1 deficiency induces RGC loss mainly through oxidative stress. In this study, intraocular injection of an NO donor to WT mice significantly upregulated AT1-R expression, suggesting that oxidative stress contributes to the upregulation of AT1-R expression in EAAC1 KO mice. Consistently, reactive oxygen species (ROS) are recognized as significant inducers of AT1$\mathrm{R}$ expression in vascular smooth muscle cells. ${ }^{33-35}$

TLRs are type 1 transmembrane proteins with an intracellular TLR/interleukin-1 receptor homology domain selectively activated by conserved pathogen-associated molecular patterns, ${ }^{36}$ and have an important role in both innate and adaptive immunity. ${ }^{37}$ Among the TLR family members, TLR4 functions as the signal-transducing receptor for LPS. TLR4 is reported to have a crucial role in LPS-induced neuronal cell death in the central nervous system. ${ }^{38}$ In addition, multiple single-nucleotide polymorphisms (SNPs) 
a

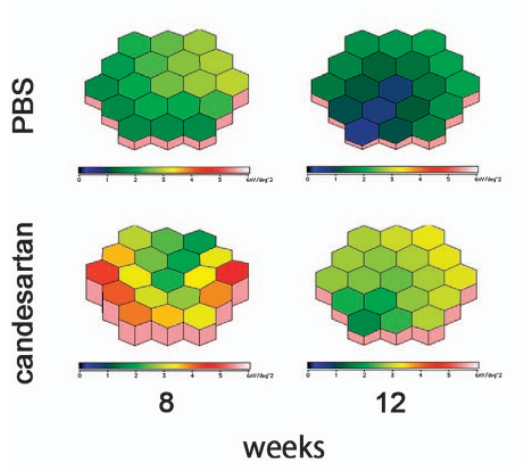

b

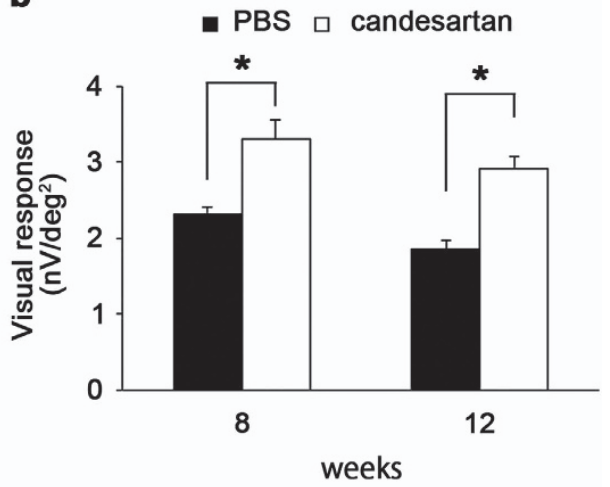

c

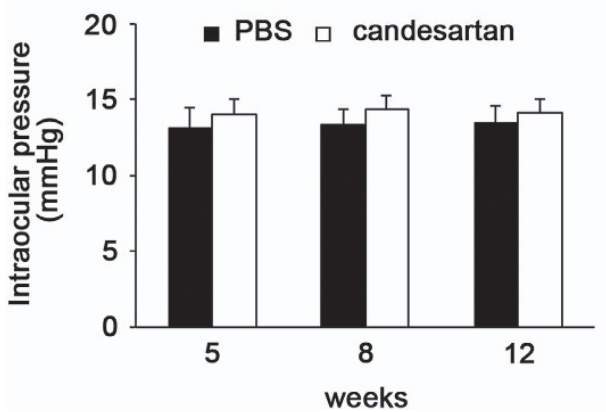

Figure 4 Effects of candesartan on visual response and intraocular pressure in EAAC1 KO mice. (a) Averaged visual responses of the second-order kernel demonstrated using three-dimensional plots. (b) Quantitative analysis of the visual response amplitude. (c) Effects of candesartan on intraocular pressure. The data are presented as means \pm S.E.M. of six samples for each experiment. ${ }^{*} P<0.05$

in the TLR4 gene have been associated with the risk of NTG, ${ }^{28}$ suggesting that TLR4 is associated with pathophysiology of glaucoma. Moreover, ASK1 is required for innate immune responses dependent on TLR4. ${ }^{39}$ ASK1 is a mitogenactivated protein kinase kinase kinase (MAP3K) that plays pivotal roles in ROS-induced cellular responses. ${ }^{15}$ In this study, we found that Müller glia, which express AT1-R, produce NO via the RAS-TLR4-ASK1 pathway. Our findings suggest that NO generation in Müller cells may be stimulated, at least partly, via an autocrine mechanism, and exacerbate RGC death in EAAC1 $\mathrm{KO}$ mice via a paracrine mechanism. Taken together, these results suggest that the RAS-TLR4ASK1 pathway has important roles in both RGCs and Müller cells, and that the glia-neuron interaction stimulates RGC death. Thus, interruption of this pathway by candesartan may be effective for neuroprotection in some types of glaucoma. To further confirm the usefulness of EAAC1 KO mice to represent glaucoma, ${ }^{40}$ we are currently investigating EAAC1 gene abnormalities in glaucoma patients. Further studies are required to determine the effects of glia-neuron interactions in various forms of retinal degeneration and during optic nerve and retinal regeneration. ${ }^{41-46}$

Recent studies reported that dysregulation of the RAS may be associated with the pathophysiology of glaucoma. ${ }^{25-26}$ In fact, oxidative stress has direct effects on RGC death through AT1-R signaling. ${ }^{29}$ In this study, we found that the RAS-TLR4-ASK1 pathway in Müller cells is involved in the production of iNOS and oxidative stress-induced RGC death in EAAC1 KO mice (Figure 8). In addition, the nitric oxide (NO) donor NOR4 significantly upregulates AT1-R expression
(Figure 5b), suggesting that NO generation in Müller cells may be further stimulated via a positive feedback mechanism. Taken together, the RAS-TLR4-ASK1 pathway may be active in both RGCs and Müller cells, and a possible therapeutic target in some types of glaucoma. As the glia-neuron network has important roles in the central nervous system, ${ }^{14,17,18,41-43}$ the RAS-TLR4-ASK1 pathway should be further elucidated using cell type-specific conditional KO mice to dissect out the roles of each cell types. We are currently preparing RGC- and Müller cell-specific ASK1 conditional $\mathrm{KO}$ mice. ${ }^{43}$

In summary, candesartan protects IOP-independent RGC death by inhibiting the RAS-TLR4-ASK1 pathway in both neural and glial cells. Our findings raise intriguing possibilities for the management of glaucoma by utilizing widely prescribed drugs for the treatment of high blood pressure, in combination with conventional treatments to lower IOP.

\section{Materials and Methods}

Mice. Experiments were performed using EAAC1 KO (Miltenyi Biotec GmbH, Bergisch Gladbach, Germany) ${ }^{6,11}$ and ASK1 KO mice ${ }^{16-18}$ on a C57BI6 background in accordance with the Tokyo Metropolitan Institute of Medical Science Guidelines for the care and use of animals.

Oral administration of candesartan. Candesartan $(10 \mathrm{mg} / \mathrm{kg}$; Takeda Chemical Industries, Osaka, Japan) in PBS was administered every day orally from 5 to 8 or $12 \mathrm{~W}$. PBS was administered as a control. The mice were euthanized for evaluation of RGC loss and IRL thickness at 5,8 and $12 \mathrm{~W}$.

Histological and morphometric studies. Paraffin embedded retinal sections of $7 \mu \mathrm{m}$ thickness were cut through the optic nerve and stained with 
a

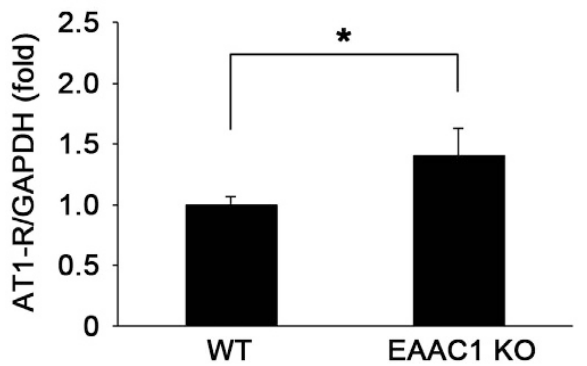

C

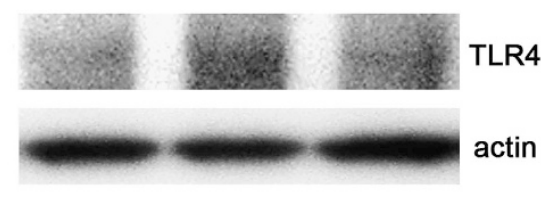

WT EAAC1 KO EAAC1 KO (candesartan)

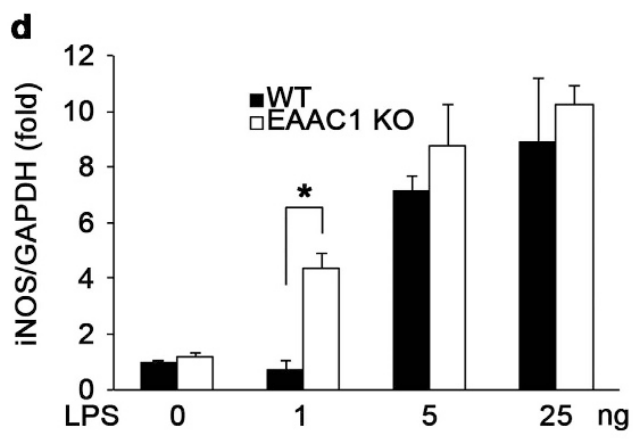

b
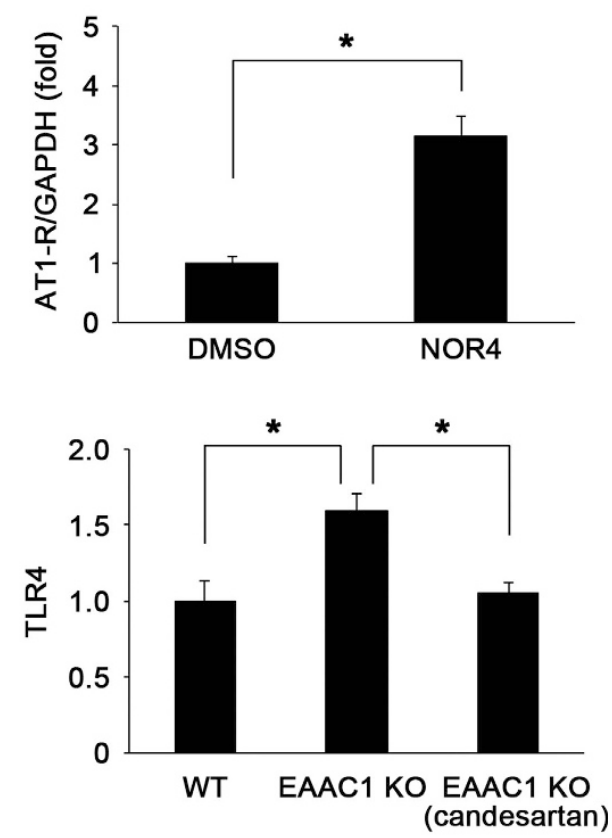

e

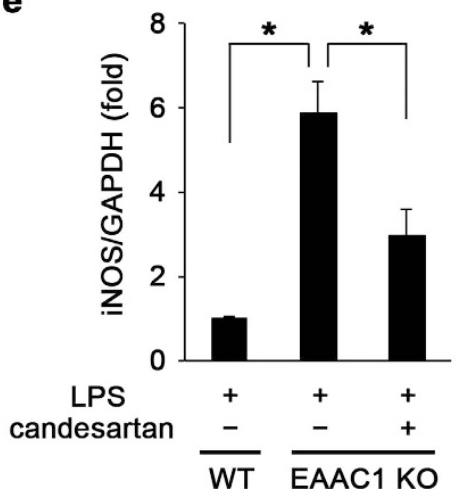

Figure 5 AT1-R and TLR4 expression levels in the EAAC1 mouse retina. (a) mRNA expression levels of AT1-R measured by quantitative real-time PCR. GAPDH was used as an internal control. (b) mRNA expression levels of AT1-R measured $9 \mathrm{~h}$ after intraocular injection of NOR4 in WT mice. (c) Protein expression levels of TLR4 were determined by western blotting before and after daily treatment with candesartan for a week. Actin was used as an internal control. (d) iNOS mRNA expression levels were measured $6 \mathrm{~h}$ after intraocular injection of LPS. (e) iNOS mRNA expression levels were measured $6 \mathrm{~h}$ after intraocular injection of LPS (1 ng) with or without daily treatment with candesartan for a week. The data are presented as means \pm S.E.M. of six samples for each experiment. ${ }^{*} P<0.05$

hematoxylin and eosin $(\mathrm{H \& E})$. The microscopic image of each section within 0.5 to $1 \mathrm{~mm}$ from the optic disk was scanned. The RGC number and the extent of retinal degeneration were quantified in two ways. First, the thickness of the IRL (between the internal limiting membrane and the interface of the outer plexiform layer and the outer nuclear layer) was analyzed. Second, in the same sections, the number of neurons in the GCL was counted from one ora serrata through the optic nerve to the other ora serrata.

Imaging acquisition of spectral-domain optical coherence tomography (SD-OCT). SD-OCT (RS-3000, Nidek, Aichi, Japan) examinations were performed at 5,8 and $12 \mathrm{~W}$. For fundus imaging, polymethyl methacrylate contact lenses optimal for mice (UNICON, Osaka, Japan) were placed on the corneas. Use of the lenses prevents anesthesia-induced cataract progression. A 60-D adaptor lens was placed on the objective lens of the Multiline OCT to focus on the mouse retina. For imaging of the inner retinal layers on SDOCT using the speckle noise-reduction method, line scans and a circular scan around the optic disk were performed. All the line scan images were location matched, scanning vertically through the center of the optic nerve head at 3 disc diameter lengths above the optic nerve head. ${ }^{17}$ All the circular scan images were obtained by scanning a circle centering around the optic nerve disk. The average thickness of GCC (between the internal limiting membrane and the interface of the inner plexiform layer and the inner nuclear layer) was measured. In this study, the maximum number of B-scans set by the manufacturer (50 for line scans and 10 for circular scans) was used for averaging.

IOP measurement. IOP was measured by a commercial rebound tonometer (TonoLab; Colonial Medical Supply, Franconia, NH, USA) in anesthetized mice as reported previously. ${ }^{14}$ To minimize variation, the data were collected during a time window of 4-6 min after injection of the anesthetic, during which IOP plateaus. IOP was measured at 5,8 and $12 \mathrm{~W}$. As the 24-h IOP pattern in mouse eyes is biphasic, with IOP being the highest at around 2100 hours, ${ }^{47}$ we examined IOP between 2000 and 2300 hours.

mfERG. Mice at 5, 8 and $12 \mathrm{~W}$ were anesthetized by intraperitoneal injection of sodium pentobarbital. The pupils were dilated with $0.5 \%$ phenylephrine hydrochloride and $0.5 \%$ tropicamide. mfERGs were recorded using a VERIS 6.0 system (Electro-Diagnostic Imaging, Redwood City, CA, USA). The visual stimulus consisted of seven hexagonal areas scaled with eccentricity. The stimulus 
a

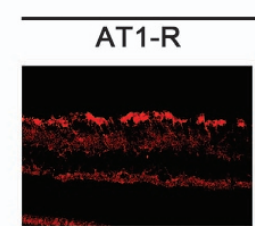

AT1-R

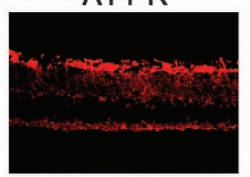

TLR4

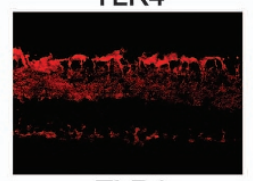

TLR4
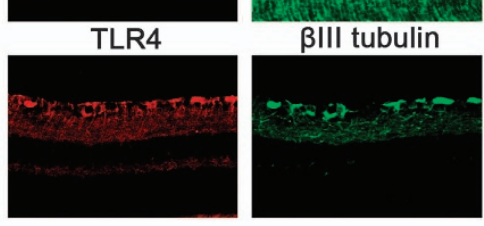

b
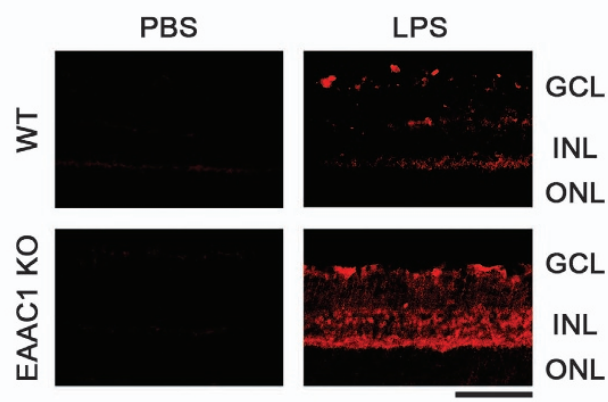

GCL

INL ONL

C

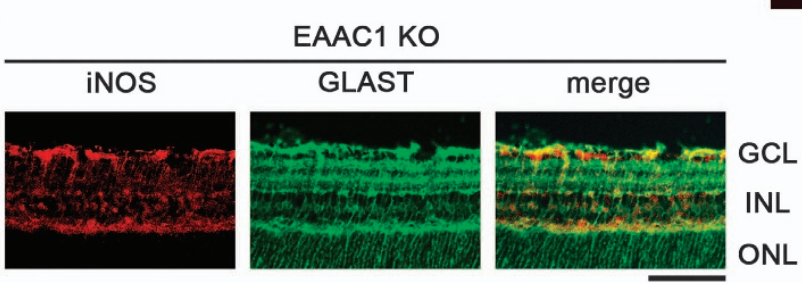

d

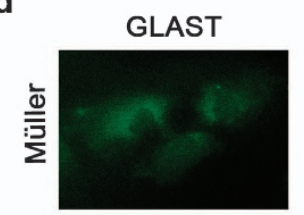

$\beta$ III tubulin

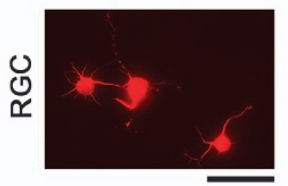

EAAC1 KO

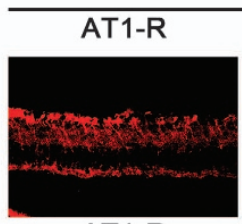

AT1-R

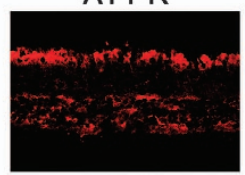

TLR4

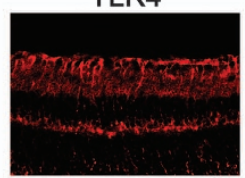

TLR4
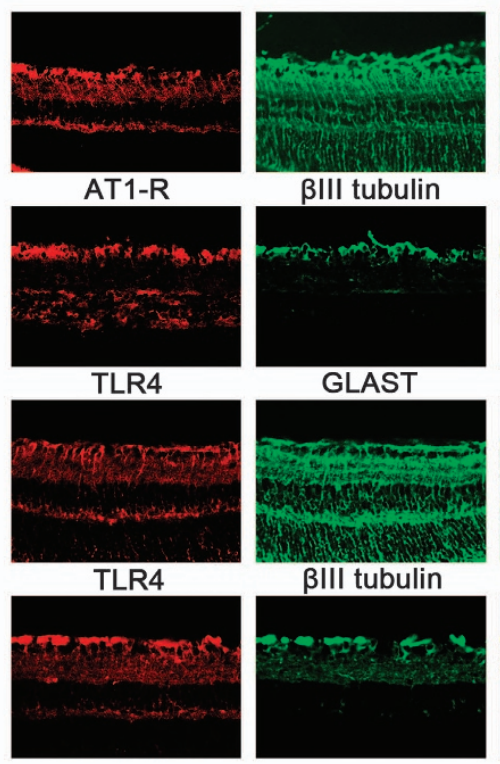

$\beta$ III tubulin

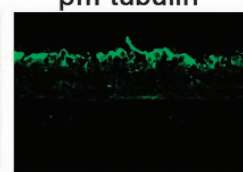

GLAST

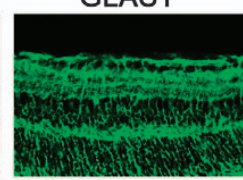

BIII tubulin

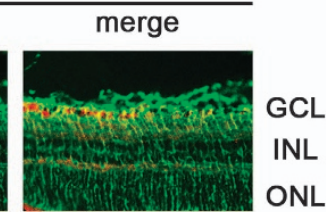

merge

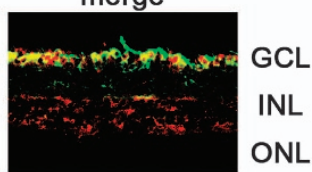

merge

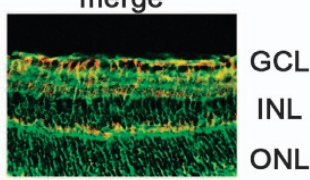

merge

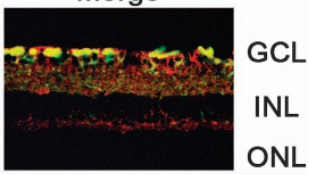

e

Müller RGC Retina
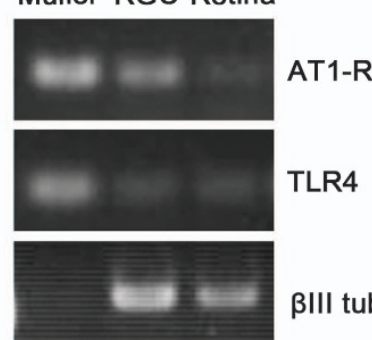

$\beta$ III tubulin

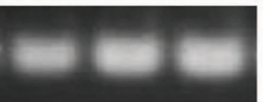

GAPDH

Figure 6 Expressions of AT1-R, TLR4 and iNOS in the EAAC1 KO mouse retina. (a) Immunostainings of AT1-R- and TLR4-positive cells (red). GS, GLAST and $\beta$ III tubulin were used as cell type-specific markers (green). Overlapping immunoreactivities (yellow) indicate that AT1-R and TLR4 are expressed in Müller cells and RGCs, and increased in EAAC1 KO mice. (b, c) Immunostaining of iNOS-positive cells (red) $6 \mathrm{~h}$ after intraocular injection of PBS or LPS (1 ng). GLAST was used as a marker for Müller cells (green). Overlapping immunoreactivities (yellow) indicate that iNOS is upregulated in Müller cells of EAAC1 KO mice. Scale bar, $100 \mu \mathrm{m}$. (d) Immunostainings of cultured Müller cells (GLAST; green) and RGCs ( $\beta$ III tubulin; red). Scale bar, $30 \mu \mathrm{m}$. (e) AT1-R and TLR4 mRNAs were detected by RT-PCR from cultured Müller cells, cultured RGCs and whole retinas. $\beta$ III tubulin was used as a marker for RGCs, and GAPDH was used as an internal control

array was displayed on a high-resolution black and white monitor driven at a frame rate of $100 \mathrm{~Hz}$. The second-order kernel, which is impaired in patients with glaucoma, was analyzed. ${ }^{48}$

Immunohistochemistry. Retinas were examined by immunostaining as previously reported. ${ }^{17}$ Immunohistochemistry was performed using the following primary antibodies: AT1-R (1: 100; AB15552, Merck Millipore, Billerica, MA, USA), TLR4 (1:100; ab22048, Abcam, Cambridge, MA, USA), GS (1:500; MAB302, Merck Millipore), GLAST (1:1000; Rb-Af660, Frontier Institute, Hokkaido, Japan), $\beta$ III tubulin (1:100; MAB1195, R\&D, Minneapolis, MN, USA and 1:100; 5568, Cell Signaling, Danvers, MA, USA) and iNOS $(1: 100 ; 610328$, BD Biosciences, San Jose, CA, USA).
Immunoblot analysis. Immunoblotting was performed as previously reported. ${ }^{7}$ Membranes were incubated with antibodies against TLR4 (1:100; sc-16240; Santa Cruz Biotechnology, Santa Cruz, CA, USA) and actin (1:1000; 612656; BD Biosciences).

Intraocular injection. Intravitreal injections were performed under a microsurgical microscope (Olympus Corporation, Tokyo, Japan) using a glass microsyringe (Ito Corporation, Shizuoka, Japan) with a 33-gauge needle (Ito Corporation). During this procedure the mice were anesthetized by intraperitoneal injection of sodium pentobarbital. Eyes were punctured at the upper temporal limbus and a volume of $2 \mu \mathrm{l}$ of NOR4 (10 mM in $10 \%$ DMSO; Dojindo Laboratories, Kumamoto, Japan), or $1 \mu$ l of LPS 
a

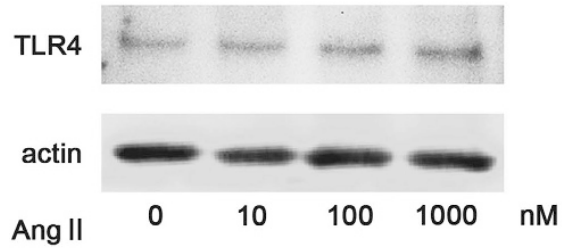

C

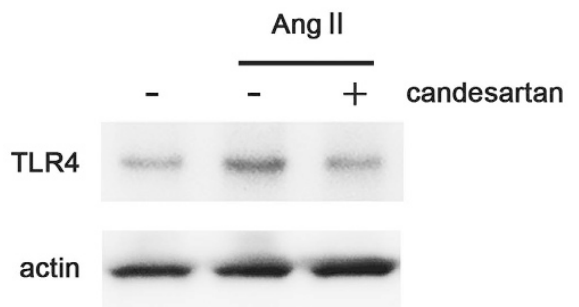

e

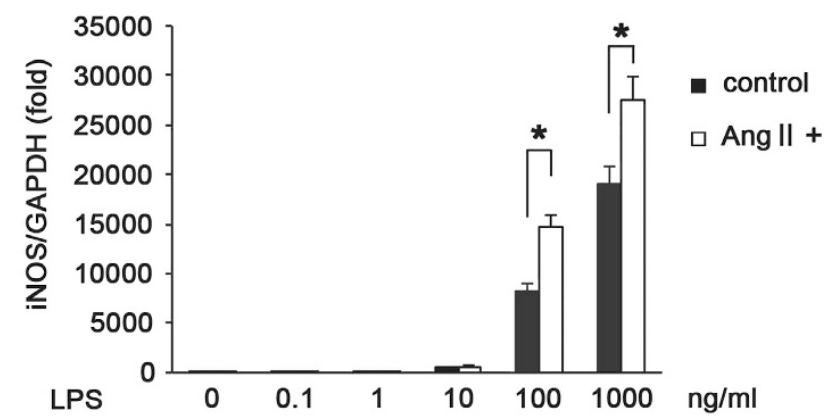

f

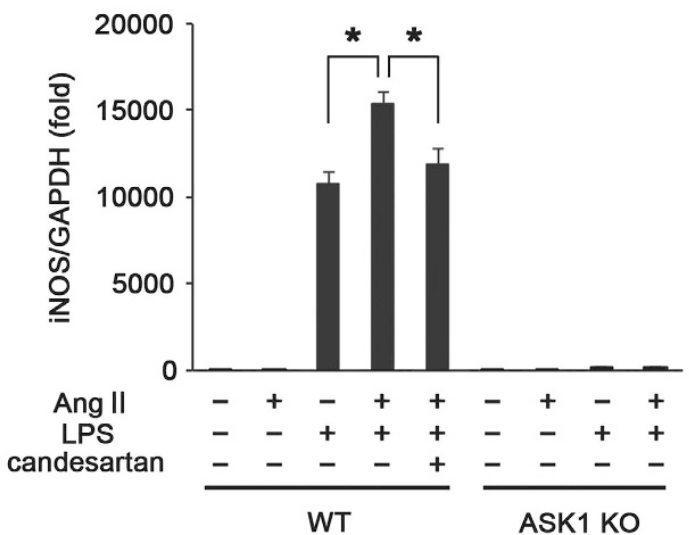

Figure 7 The TLR4-ASK1-p38 pathway is required for iNOS production in Müller cells. (a) Immunoblot analysis of TLR4 in cultured Müller cells stimulated with Angll for $24 \mathrm{~h}$. Actin was used as an internal control. (b) Quantification of TLR4 expression in a. (c) Effects of candesartan (10 $\mu \mathrm{M}$ for $1 \mathrm{~h}$ ) on Angll (1000 nM for $24 \mathrm{~h}$ )-induced TLR4 expression in cultured Müller cells. (d) Quantification of TLR4 expression in c. (e) Effects of Angll (1000 nM, 24h) and LPS on iNOS expression in cultured Müller cells. (f) Effects of candesartan ( $10 \mu \mathrm{M}$ for $1 \mathrm{~h}$ ) on iNOS expression levels in cultured Müller cells treated with Angll (1000 nM for $24 \mathrm{~h}$ ) and LPS (100 ng/ml for $6 \mathrm{~h}$ ). Cultured Müller cells were prepared from WT or ASK1 KO mice. GAPDH was used as an internal control. The data are presented as means \pm S.E.M. of six samples for each experiment. ${ }^{*} P<0.01$

$(0,1,5$ and $25 \mathrm{ng} / \mu \mathrm{l})$ or a control solution was injected. To allow diffusion of the solution, the needle was kept inside the eye for about 1 min after the delivery.
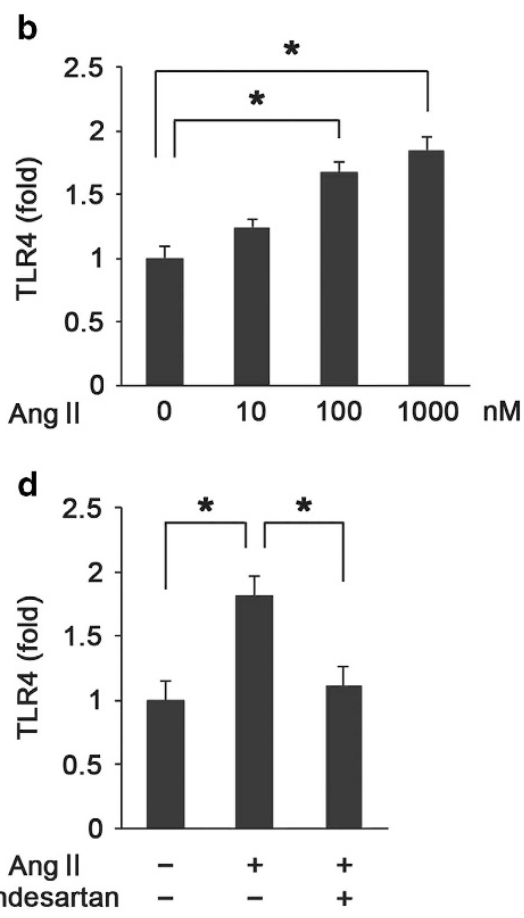

$\mathrm{ng} / \mathrm{ml}$ 


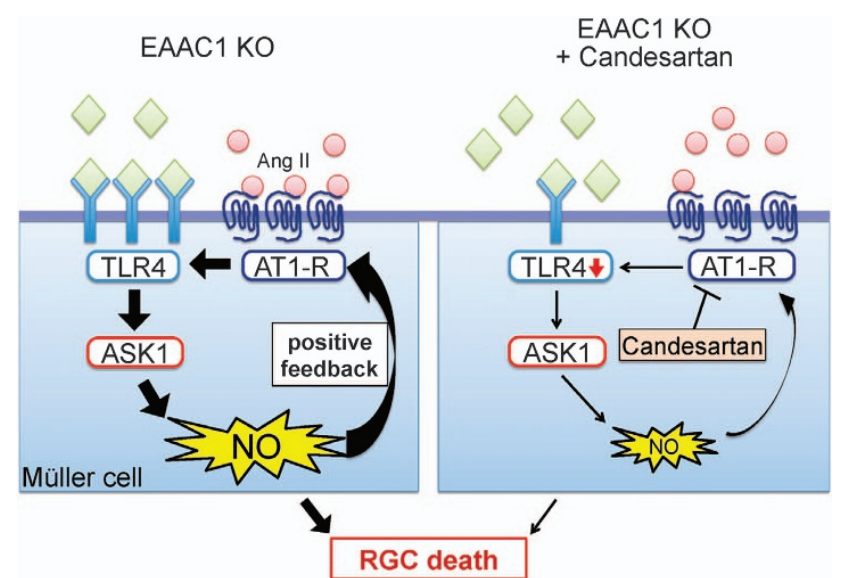

Figure 8 The proposed model of the effect of candesartan in EAAC1 KO mice. Increased oxidative stress in EAAC1 KO mice induces the upregulation of AT1-R and TLR4, resulting in increased NO expression via the ASK1 signaling pathway, which leads to RGC death. NO further stimulates AT1-R expression levels through a positive feedback loop. Candesartan blocks AT1-R and exerts neuroprotective effects by suppressing the upregulation of TLR4 and thus reducing ASK1-mediated NO production. This also results in inhibition of the positive feedback loop between NO and AT1-R

processed for quantitative PCR analysis. In some experiments, Müller cells were pretreated with candesartan ( $10 \mu \mathrm{M}$; Takeda Chemical Industries, Osaka, Japan) for $1 \mathrm{~h}$ before stimulation. RGCs were isolated by using a previously described two-step panning method. ${ }^{16,49}$ Briefly, postnatal day 2 mice were killed to obtain approximately 20 enucleated eyes. Isolated retinas were incubated in calcium- and magnesium-free Hanks' balanced salt solution containing $0.5 \mathrm{mg} / \mathrm{ml}$ papain, $0.24 \mathrm{mg} / \mathrm{ml}$ cysteine and $0.5 \mathrm{mM}$ EDTA for $10 \mathrm{~min}$ at $37^{\circ} \mathrm{C}$, and washed with PBS. The dissociated cells were incubated with rabbit anti-mouse macrophage antibody (Inter-Cell Technologies, Hopewell, NJ, USA) for $5 \mathrm{~min}$. Cell suspensions were treated for $30 \mathrm{~min}$ in $100-\mathrm{mm}$ petri dishes coated with goat antibody against rabbit IgG heavy and light chains (4050-01; Southern Biotechnology Associates, Birmingham, AL, USA). Suspensions containing the cells that did not adhere to the petri dish were treated for $1 \mathrm{~h}$ in 100-mm petri dishes coated with anti-mouse Thy 1.2 antibody (14-0902-82; eBioscience, San Diego, CA, USA). Cells that adhered to the second petri dish were collected after separation with $0.05 \%$ trypsin and $0.5 \mathrm{mM}$ EDTA at room temperature. Isolated RGCs were cultured in eight-well chamber slides. Immunohistochemistry was performed using the primary antibodies against GLAST $(1: 1000)$ and $\beta I I I$ tubulin $(1: 1000)$.

Quantitative real-time PCR. Quantitative RT-PCR was performed using the ABI 7500 fast RT-PCR system (Applied Biosystems, Foster City, CA, USA) with SYBR Green PCR Master Mix (Applied Biosystems) as previously reported..$^{50}$ Complementary DNA reverse-transcribed from total RNA was amplified by using primers specific for AT1-R (sense: 5'-GGACACTGCCATGCCCATAAC-3'; antisense: 5'-TGAGTGCGACTTGGCCTTTG-3'), TLR4 (sense: $5^{\prime}$-GCCGGAAGGTTATTGTG GTA-3'; antisense: $5^{\prime}$-TGCCATGTTTGAGCAATCTC-3'), iNOS (sense: $5^{\prime}-A$ CTGTGTGCCTGGAGGTTCT-3'; antisense: $5^{\prime}$-GGCAGCCTCTTGTCTTTG AC-3'), $\beta$ III tubulin (sense: $5^{\prime}$-CAGCGGCAACTATGTAG GGGAC-3'; antisense: $5^{\prime}$-GCCCTTTGGCCCAGTTGTTGCC-3') and GAPDH (sense: $5^{\prime}$-TG CACCACCAACTGCTTAG-3'; antisense: $5^{\prime}$-GGATGCAGGGATGATGTTC-3'). In some experiments, PCR products were separated with a $3 \%$ agarose gel.

Statistics. For statistical comparison of two samples, we used a two-tailed Student's $t$-test. Data are presented as means \pm S.E.M. $P<0.05$ was regarded as statistically significant.

\section{Conflict of Interest}

The authors declare no conflict of interest.
Acknowledgements. We are grateful to $\mathrm{H}$ Ichijo for providing ASK1-deficient mice. We thank A Kimura, D Kittaka, M Kunitomo and K Okabe for their technical support. This study was supported by the Ministry of Education, Culture, Sports, Science and Technology of Japan (KN, XG, CH, TH, YM); Takeda Science Foundation $(\mathrm{KN})$; and the Funding Program for Next Generation World-Leading Researchers (NEXT Program) (TH).

1. Quigley HA. Number of people with glaucoma worldwide. Br J Ophthalmol 1996; 80: 389-393.

2. Quigley HA, Broman AT. The number of people with glaucoma worldwide in 2010 and 2020. Br J Ophthalmol 2006; 90: 262-267.

3. Lindsey JD, Weinreb RN. Elevated intraocular pressure and transgenic applications in the mouse. J Glaucoma 2005; 14: 318-320.

4. Iwase A, Suzuki Y, Araie M, Yamamoto T, Abe H, Shirato S et al. The prevalence of primary open-angle glaucoma in Japanese: the Tajimi Study. Ophthalmology 2004; 111: 1641-1648.

5. Desai PV, Caprioli J. The treatment of normal-tension glaucoma. Prog Brain Res 2008; 173: $195-210$.

6. Harada T, Harada C, Nakamura K, Quah HA, Okumura A, Namekata K et al. The potential role of glutamate transporters in the pathogenesis of normal tension glaucoma. J Clin Invest 2007; 117: 1763-1770.

7. Namekata K, Kimura A, Kawamura K, Guo X, Harada C, Tanaka K et al. Dock3 attenuates neural cell death due to NMDA neurotoxicity and oxidative stress in a mouse model of normal tension glaucoma. Cell Death Differ 2013; 20: 1250-1256.

8. Bai N, Hayashi H, Aida T, Namekata K, Harada T, Mishina M et al. Dock3 interaction with a glutamate-receptor NR2D subunit protects neurons from excitotoxicity. Mol Brain 2013; 6: 22 .

9. Danbolt NC. Glutamate uptake. Prog Neurobiol 2001; 65: 1-105.

10. Harada $T$, Harada $C$, Watanabe M, Inoue $\mathrm{Y}$, Sakagawa $T$, Nakayama $N$ et al. Functions of the two glutamate transporters GLAST and GLT-1 in the retina. Proc Natl Acad Sci USA 1998; 95: 4663-4666.

11. Namekata K, Harada C, Guo X, Kikushima K, Kimura A, Fuse N et al. Interleukin-1 attenuates normal tension glaucoma-like retinal degeneration in EAAC1-deficient mice. Neurosci Lett 2009; 465: 160-164.

12. Osborne NN. Pathogenesis of ganglion 'cell death' in glaucoma and neuroprotection: focus on ganglion cell axonal mitochondria. Prog Brain Res 2008; 173: 339-352.

13. Naskar R, Vorwerk CK, Dreyer EB. Concurrent downregulation of a glutamate transporter and receptor in glaucoma. Invest Ophthalmol Vis Sci 2000; 41: 1940-1944.

14. Harada C, Namekata K, Guo X, Yoshida H, Mitamura Y, Matsumoto $Y$ et al. ASK1 deficiency attenuates neural cell death in GLAST-deficient mice, a model of normal tension glaucoma. Cell Death Differ 2010; 17: 1751-1759.

15. Hattori K, Naguro I, Runchel C, Ichijo H. The roles of ASK family proteins in stress responses and diseases. Cell Commun Signal 2009; 7: 9.

16. Harada C, Nakamura K, Namekata K, Okumura A, Mitamura Y, lizuka $Y$ et al. Role of apotosis signal-regulating kinase 1 in stress-induced neural cell apoptosis in vivo. Am J Pathol 2006; 168: 261-269.

17. Katome T, Namekata K, Guo X, Semba K, Kittaka D, Kawamura K et al. Inhibition of ASK1p38 pathway prevents neural cell death following optic nerve injury. Cell Death Differ 2013; 20: $270-280$.

18. Guo X, Harada C, Namekata K, Matsuzawa A, Camps M, Ji H et al. Regulation of the severity of neuroinflammation and demyelination by TLR-ASK1-p38 pathway. EMBO Mol Med 2010; 2: 504-515.

19. Baker KM, Booz GW, Dostal DE. Cardiac actions of angiotensin II: Role of an intracardiac renin-angiotensin system. Annu Rev Physiol 1992; 54: 227-241.

20. Goodfriend TL, Elliott ME, Catt KJ. Angiotensin receptors and their antagonists. N Engl J Med 1996; 334: 1649-1654.

21. Wolf G, Bohlender J, Bondeva T, Roger T, Thaiss F, Wenzel UO. Angiotensin II upregulates toll-like receptor 4 on mesangial cells. J Am Soc Nephrol 2006; 17: $1585-1593$.

22. Otsui K, Inoue N, Kobayashi S, Shiraki R, Honjo T, Takahashi M et al. Enhanced expression of TLR4 in smooth muscle cells in human atherosclerotic coronary arteries. Heart Vessels 2007; 22: 416-422.

23. Chobanian AV, Bakris GL, Black HR, Cushman WC, Green LA, Izzo JL et al. The seventh report of the joint national committee on prevention, detection, evaluation, and treatment of high blood pressure: the JNC 7 report. JAMA 2003; 289: 2560-2572.

24. Fujita T, Hirooka K, Nakamura T, Itano T, Nishiyama A, Nagai $Y$ et al. Neuroprotective effects of angiotensin II type 1 receptor (AT1-R) blocker via modulating AT1-R signaling and decreased extracellular glutamate levels. Invest Ophthalmol Vis Sci 2012; 53: 4099-4110.

25. Hashizume K, Mashima Y, Fumayama T, Ohtake Y, Kimura I, Yoshida K et al. Genetic polymorphisms in the angiotensin II receptor gene and their association with open-angle glaucoma in a Japanese population. Invest Ophthalmol Vis Sci 2005; 46: 1993-2001.

26. Hirooka K, Baba T, Fujimura T, Shiraga F. Prevention of visual field defect progression with angiotensin-converting enzyme inhibitor in eyes with normal-tension glaucoma. Am J Ophthalmol 2006; 142: 523-525. 
27. Takano $\mathrm{Y}$, Shi D, Shimizu A, Funayama T, Mashima $\mathrm{Y}$, Yasuda $\mathrm{N}$ et al. Association of Toll-like receptor 4 gene polymorphisms in Japanese subjects with primary open-angle, normal-tension, and exfoliation glaucoma. Am J Ophthalmol 2012; 154: 825-832.

28. Shibuya E, Meguro A, Ota M, Kashiwagi K, Mabuchi F, lijima H et al. Association of Toll-like receptor 4 gene polymorphisms with normal tension glaucoma. Invest Ophthalmol Vis Sci 2008; 49: 4453-4457.

29. Ozawa Y, Yuki K, Yamagishi R, Tsubota K, Aihara M. Renin-angiotensin system involvement in the oxidative stress-induced neurodegeneration of cultured retinal ganglion cells. Jpn J Ophthalmol 2013; 57: 126-132.

30. Guo L, Normando EM, Nizari S, Lara D, Cordeiro MF. Tracking longitudinal retinal changes in experimental ocular hypertension using the cSLO and spectral domain-OCT. Invest Ophthalmol Vis Sci 2010; 51: 6504-6513.

31. Nakano N, Ikeda HO, Hangai M, Muraoka Y, Toda Y, Kakizuka A et al. Longitudinal and simultaneous imaging of retinal ganglion cells and inner retinal layers in a mouse model of glaucoma induced by N-methyl-D-aspartate. Invest Ophthalmol Vis Sci 2011; 52: 8754-8762.

32. van Velthoven ME, Faber DJ, Verbraak FD, van Leeuwen TG, de Smet MD. Recent developments in optical coherence tomography for imaging the retina. Prog Retin Eye Res 2007; 26: 57-77.

33. Gragasin FS, Xu Y, Arenas IA, Kainth N, Davidge ST. Estrogen reduces angiotensin Itinduced nitric oxide synthase and $\mathrm{NAD}(\mathrm{P}) \mathrm{H}$ oxidase expression in endothelial cells. Arterioscler Thromb Vasc Biol 2003; 23: 38-44.

34. Linthout SV, Spillmann F, Lorenz M, Meloni M, Jacobs F, Egorova M et al. Vascularprotective effects of high-density lipoprotein include the downregulation of the angiotensin II type 1 receptor. Hypertension 2009; 53: 682-687.

35. Tanaka N, Miyajima A, Kosaka T, Shirotake S, Hasegawa M, Kikuchi E et al. Cis-dichlorodiammineplatinum upregulates angiotensin II type 1 receptors through reactive oxygen species generation and enhances VEGF production in bladder cancer. $\mathrm{Mol}$ Cancer Ther 2010; 9: 2982-2992.

36. Anderson KV. Toll signaling pathways in the innate immune response. Curr Opin Immuno 2002; 12: 13-19.

37. Akira S, Takeda K, Kaisho T. Toll-like receptors: critical proteins linking innate and acquired immunity. Nat Immunol 2001; 2: 675-680.

38. Lehnardt S, Massillon L, Follett P, Jensen FE, Ratan R, Rosenberg PA et al. Activation of innate immunity in the CNS triggers neurodegeneration through a Toll-like receptor 4-dependent pathway. Proc Natl Acad Sci USA 2003; 100: 8514-8519.

39. Matsuzawa A, Saegusa K, Noguchi T, Sadamitsu C, Nishitoh $H$, Nagai $S$ et al. ROS-dependent activation of the TRAF6-ASK1-p38 pathway is selectively required for TLR4-mediated innate immunity. Nat Immunol 2005; 6: 587-592.

40. Bouhenni RA, Dunmire J, Sewell A, Edward DP. Animal models of glaucoma. J Biomed Biotechnol 2012; 2012: 692609 .
41. Harada T, Harada C, Kohsaka S, Wada E, Yoshida K, Ohno S et al. Microglia-Müller glia cell interactions control neurotrophic factor production during light-induced retinal degeneration. J Neurosci 2002; 22: 9228-9236.

42. Bringmann A, Wiedemann P. Müller glial cells in retinal disease. Ophthalmologica 2012; 227: $1-19$

43. Harada C, Guo X, Namekata K, Kimura A, Nakamura K, Tanaka K et al Glia- and neuronspecific functions of TrkB signalling during retinal degeneration and regeneration. Nat Commun 2011; 2: 189.

44. Wohl SG, Schmeer CW, Isenmann S. Neurogenic potential of stem/progenitor-like cells in the adult mammalian eye. Prog Retin Eye Res 2012; 31: 213-242.

45. Namekata K, Harada C, Taya C, Guo X, Kimura H, Parada LF et al. Dock3 induces axonal outgrowth by stimulating membrane recruitment of the WAVE complex. Proc Natl Acad Sci USA 2010; 107: 7586-7591.

46. de Lima S, Habboub G, Benowitz LI. Combinatorial therapy stimulates long-distance regeneration, target reinnervation, and partial recovery of vision after optic nerve injury in mice. Int Rev Neurobiol 2012; 106: 153-172.

47. Aihara M, Lindsey JD, Weinreb RN. Twenty-four-hour pattern of mouse intraocular pressure. Exp Eye Res 2003; 77: 681-686.

48. Sutter EE, Bearse Jr MA. The optic nerve head component of the human ERG. Vision Res 1999; 39: 419-436.

49. Barres BA, Silverstein BE, Corey DP, Chun LL. Immunological, morphological, and electrophysiological variation among retinal ganglion cells purified by panning. Neuron 1988; 1: 791-803.

50. Guo X, Nakamura K, Kohyama K, Harada C, Behanna HA, Watterson DM et al. Inhibition of glial cell activation ameliorates the severity of experimental autoimmune encephalomyelitis. Neurosci Res 2007; 59: 457-466.

(2) (1) (2) Cell Death and Disease is an open-access journal BY NC sa published by Nature Publishing Group. This work is licensed under a Creative Commons Attribution-NonCommercialShareAlike 3.0 Unported License. The images or other third party material in this article are included in the article's Creative Commons license, unless indicated otherwise in the credit line; if the material is not included under the Creative Commons license, users will need to obtain permission from the license holder to reproduce the material. To view a copy of this license, visit http://creativecommons.org/ licenses/by-nc-sa/3.0/ 